\title{
Relationship between Theory of Mind and Executive Function in Schizophrenia: A Systematic Review
}

\author{
Graham J. Pickup \\ Sub-Department of Clinical Health Psychology, University College London, London, UK
}

\section{Key Words}

Theory of mind - Mentalizing · Social cognition - Executive functions $\cdot$ Schizophrenia

\begin{abstract}
Background: There is good agreement that Theory of Mind (ToM) and executive function are impaired to some degree in many patients with schizophrenia. However, few studies have set out to investigate as a primary aim the relationship between these 2 cognitive domains in the disorder. Methods: A systematic review was carried out to identify all published studies in which tests of ToM and executive function were administered to individuals with schizophrenia, and in which the relation between scores was reported. Results: The review revealed 17 relevant studies, of which 8 reported the relation between ToM and executive function using multivariate statistics. These all concurred in showing that ToM ability continued to predict an individual having schizophrenia (rather than being a control participant) once executive function was controlled for. Conclusions: There is very good agreement that ToM and executive function impairments in schizophrenia are independent of one another. Implications are discussed for the putative brain systems involved in the disorder and for its cognitive rehabilitation.
\end{abstract}

Copyright ๑ 2008 S. Karger AG, Basel (c) 2008 S. Karger AG, Basel

0254-4962/08/0414-0206\$24.50/0

Fax +4161306 1234 E-Mail karger@karger.ch www.karger.com

\section{Introduction}

In his cognitive neuropsychological model of schizophrenia, Frith $[1,2]$ suggested that particular symptoms of the disorder are associated with impairments in 'Theory of Mind' (ToM), or 'mentalizing', the ability to correctly attribute mental states such as intentions, thoughts and beliefs to other people. By drawing parallels with autistic individuals who have empirically well-established mentalizing difficulties [3], Frith proposed that ToM impairments in schizophrenia are particularly pronounced in patients with positive or negative ‘behavioural signs' of the disorder, such as inappropriate behaviour, speech or affect (positive signs) or reduced behaviour, poverty of speech or flat affect (negative signs). He further suggested that schizophrenia patients with paranoid symptoms (such as delusions of reference or persecution) have more subtle ToM impairments, as they continue to mentalize, but make errors when they infer other people's intentions and beliefs. He proposed that patients with only passivity symptoms (e.g. delusions of control) or those without current symptoms (in remission) have intact ToM. Two recent reviews of more than 30 empirical studies in this field $[4,5]$ concluded that there is considerable evidence for impaired ToM in schizophrenia, with patients performing worse than control groups on a wide range of verbal and non-verbal ToM tasks. However, further work is needed to clarify the relation between ToM impairments, symptomatology and other cognitive domains in the disorder. 
Some researchers have argued that a domain-specific cognitive 'module' [6] and dedicated neural system underlie mentalizing abilities in humans, and indeed neuroimaging studies show that a particular set of brain regions are reliably activated when healthy subjects perform ToM tasks [7]. Recent studies have suggested that different processes (e.g. seeing the world from another's perspective in cognitive or emotional terms, applying knowledge of the world, thinking about others who are similar to or different from oneself, perceiving communicative intent) are involved in ToM, and that specific brain areas may subserve each of these processes [8]. By this account, ToM impairments in schizophrenia may reflect particular problems with the ToM module, over and above other cognitive deficits characteristic of the disorder, and studies showing that patients' poor performance on ToM tasks cannot simply be explained by lower IQ [ 9 , 10] are compatible with this notion.

As discussed by Langdon et al. [11], other models propose that poor performance on ToM tasks in healthy and clinical populations reflects executive dysfunction. Executive function refers to a constellation of higher-level cognitive abilities that enable an individual to plan and execute goal-directed operations [12], and it is well established that individuals with schizophrenia perform poorly on executive tasks [13], with mounting evidence that impairments are particularly associated with the presence of positive or negative behavioural signs [14]. Langdon et al. [11] noted that if an executive dysfunction account of impaired ToM in schizophrenia is correct, it is likely that failure in 1 or both of 2 specific executive functions is to blame: (1) the ability to disengage from and inhibit salient information, such as the current state of affairs, so that less salient information (e.g. another person's belief) can be considered, and (2) the ability to manipulate representations of hypothetical situations in order to reason consequentially, predicting, for example, another person's belief about the current state of affairs based on knowledge about their exposure to a situation. The first of these abilities can be tested by attentional set-shifting tasks such as the Wisconsin Card Sorting Test (WCST) [15] and the second by strategic planning tasks such as the Tower of London (ToL) [16]. The performance of schizophrenia patients is known to be impaired on both of these tasks $[17,18]$, so it is possible that these executive difficulties could explain patients' poor performance on ToM tasks, without needing to invoke impairments in a ToM module.

Langdon et al. [11] investigated these competing accounts by administering a battery of ToM, disengagement and planning tasks to groups of schizophrenia patients and healthy controls. They used a picture-sequencing test of ToM requiring understanding of false belief (FB), and a disengagement task involving 'capture' picture-sequencing stories in which correct responding required subjects to disengage from a salient and misleading cue. Their planning task was the ToL. Consistent with previous studies, individuals with schizophrenia were impaired on both ToM and executive tasks relative to controls. Correlational data showed a strong association between patients' performance on the ToM and capture tasks, but evidence was found for the modular account of impaired mentalizing from logistic regression, which showed that ToM performance continued to predict the likelihood of being a patient when executive function was controlled for.

No other studies have had a primary aim of exploring the relation between ToM and executive function in schizophrenia, although a number of researchers have tested both cognitive domains as part of other experiments. For this paper, a literature review was planned to identify all of these other studies in order that the relation between ToM and executive function in schizophrenia could be systematically explored.

\section{Methods}

A literature review using the PsycINFO and MEDLINE databases was carried out in May 2007 to identify all published, English language studies in which both ToM and executive function tasks were given to adults with schizophrenia, and in which the relationship between scores was reported. All abstracts were read in which the search terms 'theory of mind', 'mentali?ing', 'social cognition', 'social perception' or 'perspective taking' appeared with either 'schizo*' or 'psycho?i?' in any of the key search domains. All papers in which it was possible that executive function tasks had been administered, were then read closely. The reference lists from all relevant papers were searched to identify further papers for review.

\section{Results}

Seventeen relevant studies including Langdon et al. [11] were identified (see table 1). These used a wide range of ToM tasks, including both non-verbal (e.g. FB picture-sequencing, visual jokes [33], the 'Reading the Mind in the Eyes' test [46]) and verbal (e.g. FB and deception [20], hinting [30] and irony) tasks. The latter involved sets of stories that required subjects to correctly attribute first-order (e.g. 'He thinks that...') and/or second-order (e.g. 'He thinks that he thinks that...') mental states to story characters. All of the 12 studies that used a control group found 


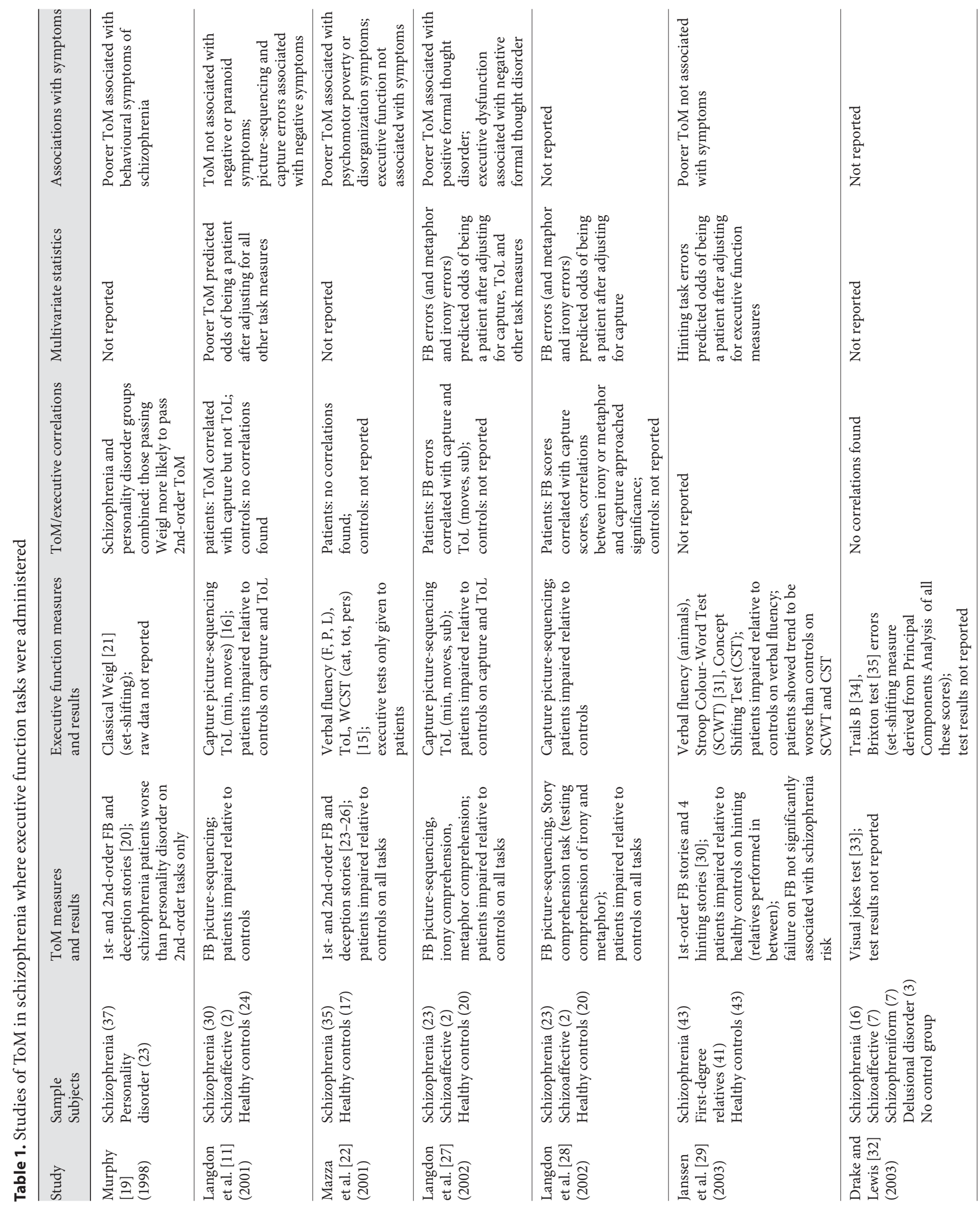




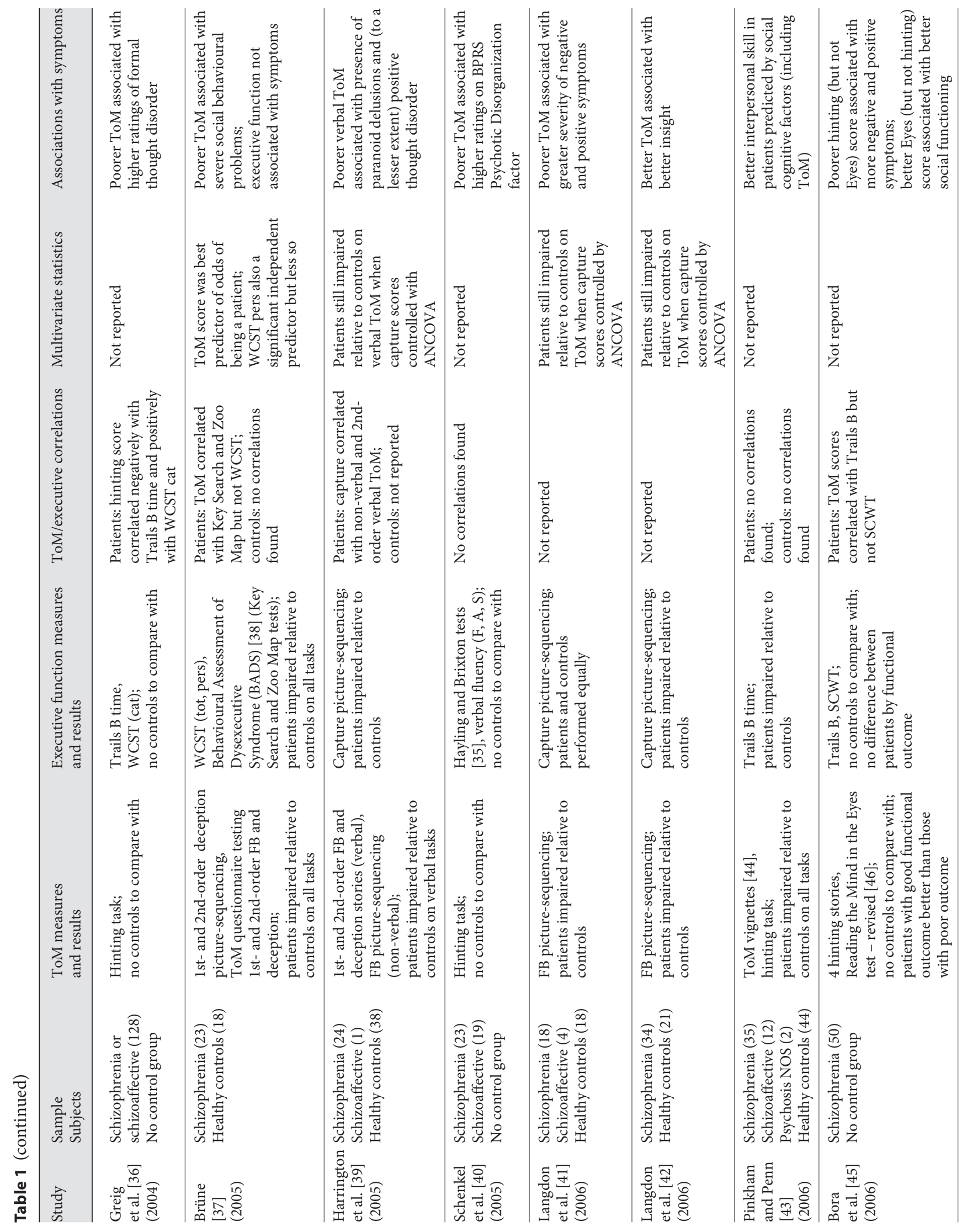




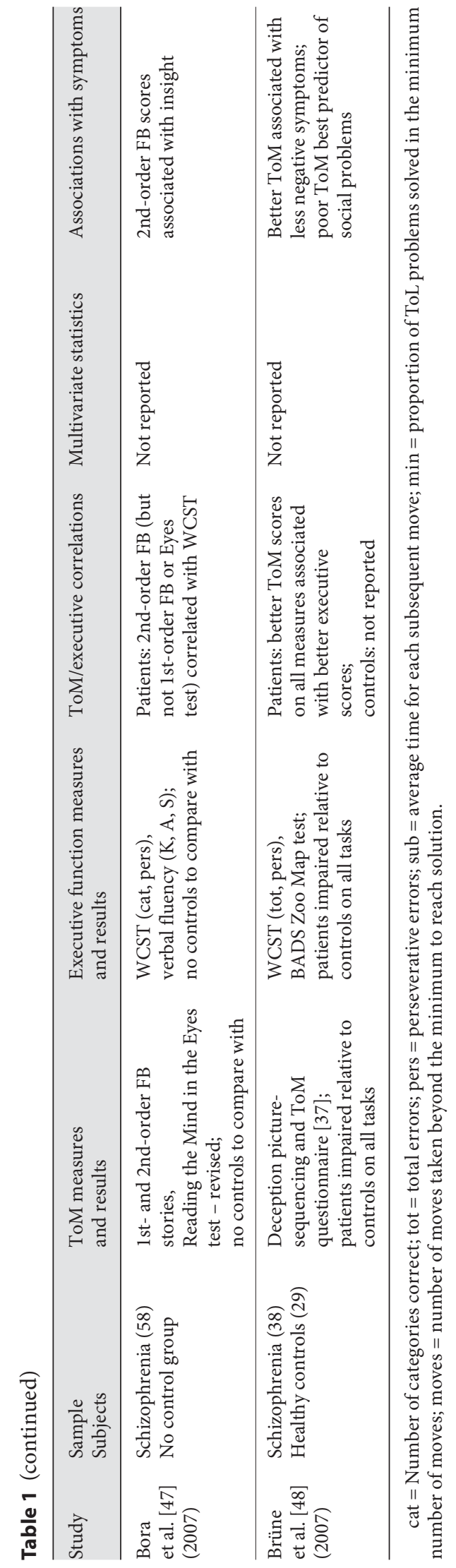

their schizophrenia patients to be significantly impaired relative to controls on most or all of the ToM tasks.

The studies similarly used a wide range of executive function measures. Those testing the ability to disengage from and inhibit salient information included the capture picture-sequencing task discussed above, the classical Weigl [21], the WCST (e.g. number of categories correct, total errors, perseverative errors) [15], the Hayling and Brixton tests [35], the interference score of the Stroop Colour-Word Test [31], Trails B time and errors [34] and the interference score of the Concept Shifting Test, a modified version of Trails B. Where data were reported, patients with schizophrenia were generally significantly impaired on these tasks relative to controls. The measures used to test strategic planning in the identified studies were the ToL (e.g. initial planning time, average time for each subsequent move, proportion of ToL problems solved in the minimum number of moves, number of moves taken beyond the minimum to reach solution) [16], and the Key Search and Zoo Map subtests of the Behavioural Assessment of Dysexecutive Syndrome [38]. Again, patients with schizophrenia were impaired on these tasks relative to controls (see table 1).

Fourteen of the studies reported correlational data regarding the relation between ToM and executive function, and with the exception of Mazza et al. [22], Schenkel et al. [40] and Pinkham and Penn [43] all found some significant correlations between the domains. Generally, whether the executive tasks measured disengagement or planning, patients' scores correlated with ToM performance in about $65 \%$ of cases. Three studies reported separate correlational data for healthy controls, and in all cases no associations were found. At first sight, the findings support the executive dysfunction account of impaired ToM in schizophrenia. However, the correlations could simply reflect shared task variance, and a better way of testing the competing accounts is to explore independent effects using multivariate statistics. This was done in 8 of the reviewed studies [11, 27-29, 37, 39, 41, 42] and all of these concurred in showing that ToM ability continued to predict that an individual had schizophrenia, rather than being a healthy control, once executive function was controlled.

\section{Discussion}

This paper reviewed the 17 published studies in which both ToM and executive function tasks were administered to patients with schizophrenia. Despite the use of 
many different tasks across studies, a highly consistent picture emerged. All studies found that schizophrenia patients were impaired in both cognitive domains relative to controls. Furthermore, all studies that explored independent effects concurred in showing that ToM and executive function impairments were independent. Together, these data provide strong evidence that impaired ToM in schizophrenia reflects dysfunction of a domainspecific cognitive system, rather than a domain-general executive impairment.

The independence of ToM and executive function in schizophrenia is consistent with a number of studies showing dissociations between these cognitive domains in other disorders [49]. For example, a case study by Lough et al. [50] of a patient with frontotemporal dementia found relatively intact executive function but extremely poor performance on a wide range of ToM tasks. Similarly, in a study of 31 patients with unilateral frontal lobe lesions, Rowe et al. [51] found that they were impaired relative to healthy controls on both ToM and executive function tasks, and that these deficits were independent. These findings are consistent with suggestions that separate brain regions subserve ToM ability and executive function in adults. In a review of functional imaging studies, Gallagher and Frith [7] concluded that 3 areas, the anterior paracingulate cortex, the superior temporal sulci and the temporal poles bilaterally, are reliably activated in healthy adults during ToM tasks. In contrast, many tests of executive function (e.g. the WCST) are thought to rely upon intact dorsolateral prefrontal cortex (DLPFC) [52]. There is mounting evidence that all of these brain regions show abnormalities in schizophrenia, and it is possible that impairments in these different regions underlie the independent deficits in ToM and executive functions in the disorder. For example, a recent review of neuroimaging studies in which schizophrenia patients performed ToM tasks, [53] found good evidence for an abnormal haemodynamic response in medial prefrontal cortex (MPFC) in patients relative to controls. Furthermore, Weinberger et al. [54] found DLPFC under-activation relative to healthy controls when individuals with schizophrenia performed the WCST.

In future research, it would be helpful for a functional imaging study to administer both ToM and executive function tasks to schizophrenia patients and controls, in order to explore the brain regions subserving these functions within the same sample. We might expect that while both types of task will activate some of the same brain regions because of shared task demands, each will additionally activate unique areas, such as the DLPFC (for executive tasks involving disengagement or set-shifting) and the MPFC for ToM tasks. Notably, a recent longitudinal functional imaging study [55] investigated performance of schizophrenia patients and controls on a social cognition paradigm requiring empathic and forgivability judgements. Following recovery from an acute episode, the patients showed greater activation in the left MPFC when performing the task, and this was correlated with improved insight and social functioning. In contrast, improved WCST performance was not associated with this increase in MPFC activation.

The cognitive deficits associated with schizophrenia have a significant impact on patients' community functioning, including social and occupational functioning and activities of daily living. In 2 reviews, Green [56] and Green et al. [57] concluded that better verbal memory, vigilance and executive function are particularly associated with better functional outcome in the disorder. However, as discussed by Pinkham et al. [58], the relation between traditional neurocognitive measures and psychosocial function is quite modest, and there is a strong argument for examining specific aspects of social cognition in schizophrenia in more detail, as they may be able to independently account for variance in social functioning. Pinkham et al. [58] reviewed a number of studies showing that aspects of social cognition such as facial affect and social cue perception are related to social functioning in schizophrenia, and that this relation is often independent of other cognitive deficits. It is as yet unclear to what extent these different domains of social cognition are related to ToM in schizophrenia [59], but the conclusion from the present review that executive function and ToM are independent in the disorder suggests that future research could usefully explore the relation between ToM and social function, as ToM may independently account for significant variance in functioning. Interestingly, several recent studies $[37,43,60]$ found that when ToM tasks and standard neurocognitive batteries were administered to individuals with schizophrenia, ToM scores were good predictors of social functioning. This may have important implications for psychosocial rehabilitation in the disorder because specific improvements in patients' ToM ability may have a substantial impact on their social function. Recent evidence suggests that, contrary to Frith's original hypothesis [1], ToM impairments in schizophrenia may be both a trait and state deficit, present (to some degree) in remitted patients $[61,62]$ as well as in those with active symptoms. This indicates the potential importance of focusing on ToM in the rehabilitation of all schizophrenia patients, whether they are symptomatic or not. 


\section{References}

1 Frith CD: The Cognitive Neuropsychology of Schizophrenia. Hillsdale, Erlbaum Associates Ltd, 1992.

$\checkmark 2$ Frith CD: Schizophrenia and theory of mind: editorial. Psychol Med 2004;34:385-389.

3 Baron-Cohen S, Tager-Flusberg H, Cohen DJ: Understanding Other Minds. Perspectives from Developmental Cognitive Neuroscience. Oxford, Oxford University Press, 2000.

4 Brüne M: 'Theory of mind' in schizophrenia: a review of the literature. Schizophr Bull 2005;31:1-22.

5 Harrington L, Siegert RJ, McClure J: Theory of mind in schizophrenia: a critical review. Cognit Neuropsychiatry 2005;10:249-286.

-6 Scholl BJ, Leslie A: Modularity, development and 'theory of mind'. Mind Lang 1999;14: 131-153.

7 Gallagher HL, Frith CD: Functional imaging of 'theory of mind'. Trends Cogn Sci 2003;7: 77-83.

$>8$ Frith CD, Frith U: The neural basis of mentalizing. Neuron 2006;50:531-534.

$>9$ Doody GA, Götz M, Johnstone EC, Frith CD, Cunningham-Owens DG: Theory of mind and psychoses. Psychol Med 1998;28:397405.

10 Pickup GJ, Frith CD: Theory of mind impairments in schizophrenia: symptomatology, severity and specificity. Psychol Med 2001;31:207-220.

11 Langdon R, Coltheart M, Ward PB, Catts SV: Mentalising, executive planning and disengagement in schizophrenia. Cognit Neuropsychiatry 2001;6:81-108.

$\checkmark 12$ Velligan DC, Bow-Thomas CC: Executive function in schizophrenia. Semin Clin Neuropsychiatry 1999;4:24-33.

$\checkmark 13$ Chan RCK, Chen EYH, Cheung EFC, Cheung HK: Executive dysfunctions in schizophrenia: relationships to clinical manifestation. Eur Arch Psychiatry Clin Neurosci 2004; 254:256-262.

-14 Basso MR, Nasrallah HA, Olson SC, Bornstein RA: Neuropsychological correlates of negative, disorganized and psychotic symptoms in schizophrenia. Schizophr Res 1998; 31:99-111.

15 Heaton RK: A Manual for the Wisconsin Card Sorting Test. Odessa, Psychological Assessment Resources, 1981.

16 Shallice T: Specific impairments of planning. Philos Trans R Soc Lond B 1982;198: 199-209.

-17 Gold JM, Carpenter C, Randolph C, Goldberg TE, Weinberger DR: Auditory working memory and Wisconsin Card Sorting Test performance in schizophrenia. Arch Gen Psychiatry 1997;54:159-165.

- 18 Morris RG, Rushe T, Woodruffe PWR, Murray $\mathrm{R}$ : Problem-solving in schizophrenia: a specific deficit in planning ability. Schizophr Res 1995; 14:235-246.
19 Murphy D: Theory of mind in a sample of men with schizophrenia detained in a special hospital: its relationship to symptom profiles and neuropsychological tests. Crim Behav Ment Health 1998;8:13-26.

20 Frith CD, Corcoran R: Exploring 'theory of mind' in people with schizophrenia. Psychol Med 1996;26:521-530.

21 Weigl E: On the psychology of so-called processes of abstraction. J Norm Soc Psychol 1941;36:3-33.

22 Mazza M, DeRisio A, Surian L, Roncone R, Casacchia M: Selective impairments of theory of mind in people with schizophrenia. Schizophr Res 2001;47:299-308.

23 Baron-Cohen S, Leslie A, Frith U: Does the autistic child have a 'Theory of Mind'? Cognition 1985;21:37-46.

24 Happé FGE: An advanced test of theory of mind: understanding of story characters' thoughts and feelings by able autistics, mentally handicapped and normal children and adults. J Autism Dev Disord 1994;24:129_ 154.

25 Baron-Cohen S: The autistic child's theory of mind: a case of specific developmental delay. J Child Psychol Psychiatry 1989;30:285297.

26 Happé FGE, Frith U: Theory of mind in autism; in Schopler E, Mesibov G (eds): Learning and Cognition in Autism. New York, Plenum Press, 1994.

27 Langdon R, Coltheart M, Ward PB, Catts SV: Disturbed communication in schizophrenia: the role of poor pragmatics and poor mind-reading. Psychol Med 2002;32:12731284.

28 Langdon R, Davies M, Coltheart M: Understanding minds and understanding communicated meanings in schizophrenia. Mind Lang 2002;17:68-104

29 Janssen I, Krabbendam L, Jolles J, van Os J: Alterations in theory of mind in patients with schizophrenia and non-psychotic relatives. Acta Psychiatr Scand 2003;108:110117.

30 Corcoran R, Mercer G, Frith CD: Schizophrenia, symptomatology and social inference: investigating 'theory of mind' in people with schizophrenia. Schizophr Res 1995; 17:5-13.

31 Stroop JR: Studies of interference in serial verbal reactions. J Exp Psychol 1935;18:643662.

>32 Drake RJ, Lewis SW: Insight and neurocognition in schizophrenia. Schizophr Res 2003; 62:165-173.

33 Corcoran R, Cahill C, Frith CD: The appreciation of visual jokes in people with schizophrenia: a study of 'mentalizing' ability. Schizophr Res 1997;24:319-327.
34 Reitan C: The Trail Making Test. Manual for Administration and Scoring. Tucson, Reitan Neuropsychological Laboratory, 1992.

35 Burgess PW, Shallice T: The Hayling and Brixton Tests. Bury St Edmunds, Thames Valley Test Company, 1997.

36 Greig TC, Bryson GJ, Bell MD: Theory of mind performance in schizophrenia: diagnostic, symptom and neuropsychological correlates. J Nerv Ment Dis 2004;192:12-18.

$\checkmark 37$ Brüne M: Emotion recognition, 'theory of mind', and social behaviour in schizophrenia. Psychiatry Res 2005; 133:135-147.

38 Wilson BA, Alderman N, Burgess P, Emslie $\mathrm{H}$, Evans JJ: Behavioural Assessment of the Dysexecutive Syndrome (BADS). Bury St Edmunds, Thames Valley Test Company, 1996.

39 Harrington L, Langdon R, Siegert RJ, McClure J: Schizophrenia, theory of mind and persecutory delusions. Cognit Neuropsychiatry 2005;10:87-104.

40 Schenkel LS, Spaulding WD, Silverstein SM: Poor premorbid social functioning and theory of mind deficit in schizophrenia: evidence of reduced context processing? J Psychiatr Res 2005;39:499-508.

41 Langdon R, Coltheart M, Ward PB: Empathetic perspective-taking is impaired in schizophrenia: evidence from a study of emotion attribution and theory of mind. Cognit Neuropsychiatry 2006;11:133-155.

42 Langdon R, Corner T, McLaren J, Ward PB, Coltheart M: Externalizing and personalizing biases in persecutory delusions: the relationship with poor insight and theory-ofmind. Behav Res Ther 2006;44:699-713.

43 Pinkham AE, Penn DL: Neurocognitive and social cognitive predictors of interpersonal skill in schizophrenia. Psychiatry Res 2006; 143:167-178.

44 Corcoran R: Theory of mind and schizophrenia; in Corrigan PW, Penn DL (eds): Social Cognition and Schizophrenia. Washington, American Psychological Association, 2001.

45 Bora E, Eryavuz A, Kayahan B, Sungu G, Veznedaroglu B: Social functioning, theory of mind and neurocognition in outpatients with schizophrenia; mental state decoding may be a better predictor of social functioning than mental state reasoning. Psychiatry Res 2006;145:95-103.

46 Baron-Cohen S, Wheelwright S, Hill J, Raste Y, Plumb I: The 'Reading the Mind in the Eyes' test revised version: a study with normal adults, and adults with Asperger syndrome or high-functioning autism. J Child Psychol Psychiatry 2001;42:241-251.

-47 Bora E, Sehitoglu G, Aslier M, Atabay I, Veznedaroglu B: Theory of mind and unawareness of illness in schizophrenia: is poor insight a mentalizing deficit? Eur Arch Psychiatry Clin Neurosci 2007;257:104-111. 
-48 Brüne M, Abdel-Hamid M, Lehmkämper C, Sonntag C: Mental state attribution, neurocognitive functioning, and psychopathology: what predicts poor social competence in schizophrenia best? Schizophr Res 2007;92: 151-159.

49 Lee K-H, Farrow TFD, Spence SA, Woodruff PWR: Social cognition, brain networks and schizophrenia. Psychol Med 2004;34:391400.

50 Lough S, Gregory C, Hodges JR: Dissociation of social cognition and executive function in frontal variant frontotemporal dementia. Neurocase 2001;7:123-130.

-51 Rowe AD, Bullock PR, Polkey CE, Morris RG: 'Theory of mind' impairments and their relationship to executive functioning following frontal lobe excisions. Brain 2001;124: 600-616.

52 Fuster JM: The Prefrontal Cortex. Anatomy, Physiology and Neuropsychology of the Frontal Lobe. New York, Raven, 1989.
53 Brunet-Gouet E, Decety J: Social brain dysfunctions in schizophrenia: a review of neuroimaging studies. Psychiatry Res 2006;148: 75-92.

54 Weinberger DR, Berman KF, Zec RF: Physiological dysfunction of dorsolateral prefrontal cortex in schizophrenia. I. Regional cerebral blood flow (rCBF) evidence. Arch Gen Psychiatry 1986;43:114-124.

55 Lee K-H, Brown WH, Egleston PN, Green RDJ, Farrow TFD, Hunter MD, Parks RW, Wilkinson ID, Spence SA, Woodruff PWR: A functional magnetic resonance imaging study of social cognition in schizophrenia during an acute episode and after recovery. Am J Psychiatry 2006;163:1926-1933.

56 Green MF: What are the functional consequences of neurocognitive deficits in schizophrenia? Am J Psychiatry 1996;153:321330.

57 Green MF, Kern RS, Braff DL, Mintz J: Neurocognitive deficits and functional outcome in schizophrenia: are we measuring the 'right stuff'? Schizophr Bull 2000;26:119-136.

58 Pinkham AE, Penn DL, Perkins DO, Lieberman J: Implications for the neural basis of social cognition for the study of schizophrenia. Am J Psychiatry 2003;160:815-824.
59 Sergi MJ, Rassovsky Y, Widmark C, Reist C, Erhart S, Braff DL, Marder SR, Green MF: Social cognition in schizophrenia: relationships with neurocognition and negative symptoms. Schizophr Res 2007;90:316-324.

60 Roncone R, Falloon IRH, Mazza M, De Risio A, Pollice R, Necozione S, Morosini P, Casacchia M: Is Theory of Mind in schizophrenia more strongly associated with clinical and social functioning than with neurocognitive deficits? Psychopathology 2002;35: 280-288.

61 Herold R, Tényi T, Lénárd K, Trixler M: Theory of mind deficit in people with schizophrenia during remission. Psychol Med 2002;32:1125-1129.

62 Inoue Y, Yamada K, Hirano M, Shinohara M, Tamaoki T, Iguchi H, Tonooka Y, Kanba S: Impairment of theory of mind in patients in remission following first episode of schizophrenia. Eur Arch Psychiatry Clin Neurosci 2006;256:326-328. 